\title{
Induction of apoptosis in rat peripheral blood lymphocytes by the anticancer drug Cl-994 (acetyldinaline) ${ }^{*}$
}

\author{
Michael J. Graziano, ${ }^{\dagger}$ Teresa A. Spoon, ${ }^{\ddagger}$ Erin A. Cockrell, ${ }^{\S}$ Paul E. Rowse, and Andrea J. Gonzales \\ Drug Safety Evaluation, Pfizer Global Research and Development, \\ 2800 Plymouth Road, Ann Arbor, Michigan 48105, USA
}

\begin{abstract}
CI-994 (acetyldinaline) is an investigational anticancer drug currently in clinical trials. In preclinical safety studies in rats and dogs, CI-994 resulted in significant toxicity to bone marrow and lymphoid tissue. To determine if apoptosis was involved in CI-994 toxicity, peripheral blood lymphocytes were isolated from untreated male Wistar rats and exposed to CI-994 (1, 3, 10, or 30 $\mu \mathrm{M})$ in vitro for up to 24 hours. Morphological and biochemical features of apoptosis were evaluated using several techniques, and lactate dehydrogenase $(\mathrm{LDH})$ release was measured as an indicator of cell necrosis. No evidence of apoptosis or necrosis was detected in lymphocytes exposed to CI-994 for 4 hours. After 24 hours, concentration-dependent increases in apoptosis characterized by DNA condensation, DNA fragmentation, and/or externalization of phosphatidyl serine were seen at CI-994 concentrations as low as $1 \mu \mathrm{M}$ and were statistically significant beginning at $10 \mu \mathrm{M}$. Ultrastructural analysis confirmed the presence of DNA condensation, DNA fragmentation, cell shrinkage, and membrane blebbing in cells exposed to $30 \mu \mathrm{M}$ CI-994. After 24 hours, the percent of maximum LDH release from lymphocytes treated with 10 and $30 \mu \mathrm{M}$ CI-994 was $7 \%$ and $15 \%$, respectively, compared with $0 \%$ in the controls. In comparison, morphological changes of apoptosis detected by fluorescent microscopy were observed in $79 \%$ of the lymphocytes at these two concentrations. Additionally, apoptosis was seen in more than $24 \%$ of lymphocytes exposed to 1 and $3 \mu \mathrm{M}$ CI-994, whereas maximum LDH release was less than or equal to $1 \%$ at these concentrations. These results show that apoptosis is the primary mode of cell death in rat lymphocytes exposed to CI-994 in vitro.
\end{abstract}

\section{INTRODUCTION}

CI-994 (acetyldinaline; Figure 1) is an investigational anticancer drug with activity in a broad spectrum of mouse, rat, and human tumor models [1-5]. CI-994 can also potentiate the activity of other standard chemotherapeutic agents. For example, simultaneous administration of CI-994 and gemcitabine results in greater than additive activity in a preclinical model of squamous cell lung carcinoma [6]. Although the mechanism of action of CI-994 is unknown, it appears to be novel when compared with other existing anticancer agents. CI-994 is not an antimetabolite, does not covalently bind to or intercalate DNA, and does not affect microtubule synthesis [7]. Studies have shown that CI-994 can inhibit a $16 \mathrm{kDa}$ nuclear phosphoprotein and increase histone acetylation $[8,9]$. Currently, CI-994 is in phase II clinical trials.

Despite an unknown mechanism of action, the toxicity of CI-994 is similar to many other cytotoxic anticancer drugs in that it primarily involves effects on bone marrow, lymphoid tissue, and testes [10-13]. When CI-994 was administered orally to Wistar rats or beagle dogs once daily for two weeks, toxicity in both species included neutropenia, lymphocytopenia, thrombocytopenia, lymphoid depletion, bone marrow hypocellularity, and testicular degeneration [10]. Lymphocytopenia and depletion of lymphoid tissue were also noted in

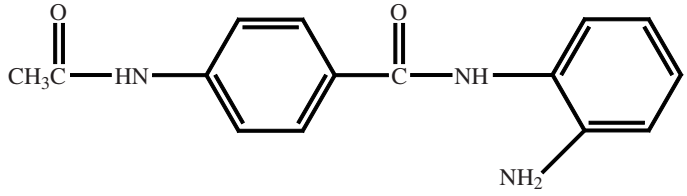

FIGURE 1: Chemical structure of CI-994.

rats within 24 hours of a single oral dose of CI-994 [11]. In mice, neutropenia, lymphocytopenia, and thrombocytopenia were observed when CI-994 was administered orally for 14 days [12]. Neutropenia and thrombocytopenia were also the dose-limiting toxicities of CI-994 in a phase I clinical trial [13]. Collectively, these results demonstrate that peripheral blood lymphocytes represent a toxicologically relevant model for studying the mechanism of CI-994 toxicity in vitro.

Since myelosuppression was observed in all species and was the dose-limiting toxicity in humans, characterizing CI994 toxicity in hematopoietic cells is of great interest. Toxicity can lead to cell death by two distinct processes; necrosis or apoptosis [14-18]. Necrosis is a more passive form of cell death that is characterized by metabolic collapse resulting from severe pathologic- or chemical-induced injury. During necrosis, cells lose their ability to maintain osmotic balance 
due to a depletion of ATP. This, in turn, leads to swelling of organelles and lysis of the plasma membrane. Necrosis is often associated with extensive tissue damage and an intense inflammatory response. Apoptosis, on the other hand, is an active process that can occur under normal physiological conditions as well as in response to chemical injury. Apoptosis involves the activation of various cell signaling cascades which results in characteristic morphological and biochemical changes such as cell shrinkage, membrane blebbing, DNA condensation, and fragmentation. The cell is eventually broken down into smaller membrane-bound vesicles termed apoptotic bodies that become engulfed by surrounding cells without initiating an inflammatory response.

The objective of the present study was to investigate whether CI-994 induced apoptosis in peripheral blood lymphocytes, one of the cell types depleted during CI-994 treatment in vivo. Specifically, peripheral blood lymphocytes were isolated from male Wistar rats and morphological and biochemical features of apoptosis were assessed following incubation with CI-994 for up to 24 hours. Multiple techniques were used in this study since it is well recognized that no single assay is sufficient for unambiguous classification of apoptotic cells [19]. LDH release (indicating altered membrane permeability) was also measured as an indicator of necrosis. The results showed that apoptosis was the primary mode of cell death in rat lymphocytes exposed to CI-994 in vitro.

\section{MATERIALS AND METHODS}

\section{Chemicals}

CI-994 (97.6\% active) was synthesized at Goedecke AG Research and Development (Freiburg, Germany). Stock solutions of CI-994 were prepared in 100\% ethanol and further diluted with sterile water to achieve the appropriate test concentrations. The intended drug concentration of each solution was confirmed analytically. Solutions were stored at room temperature. All other chemicals, unless noted, were purchased from Sigma Chemical Co. (St. Louis, MO).

\section{Isolation and treatment of peripheral blood lymphocytes}

Random-bred, male Wistar (Crl:(WI)BR) rats were obtained from Charles River Laboratories (Portage, MI). Animals were housed individually in stainless steel cages and were maintained in environmentally controlled rooms with a $12 \mathrm{~h}$ light/dark cycle. Powdered Purina Certified Rodent Chow 5002® (Ralston Purina, St. Louis, MO) and tap water were provided ad libitum. Animals were acclimated to the laboratory environment for a minimum of 7 days prior to use on study. This study was conducted according to current guidelines for the care and use of laboratory animals [20] and was approved by the Pfizer Animal Care and Use Committee.

Clinically acceptable rats weighing more than $170 \mathrm{~g}$ were used on study. Animals were euthanized by carbon dioxide inhalation and blood samples were collected in hep- arinized tubes by cardiac puncture. Blood was diluted in supplemented Hank's Balanced Salt Solution (Gibco BRL, Grand Island, NY) containing 5\% FBS (Hyclone, Logan, UT), $100 \mathrm{U} / \mathrm{ml}$ penicillin, and $0.1 \%$ streptomycin (Gibco BRL) to yield a final volume of $24.5 \mathrm{ml}$. The diluted blood samples were layered on top of Histopaque 1077 (Ficoll/sodium diatrizoate) and centrifuged at $425 \times \mathrm{g}$ for 30 minutes at room temperature. The mononuclear cell layer was removed and washed three times with supplemented Hank's Balanced Salt Solution $(300 \times \mathrm{g}, 10$ minutes $)$. Following the last wash, cells were counted and resuspended in supplemented RPMI-1640 media (Gibco BRL), pH 6.8, containing $25 \mathrm{mM}$ Hepes, $10 \%$ FBS, $100 \mathrm{U} / \mathrm{ml}$ penicillin, and $0.1 \%$ streptomycin to give a final concentration of $1 \times 10^{6} \mathrm{cells} / \mathrm{ml}$. A fixed number of cells were added to 96 -well microtiter plates $\left(2 \times 10^{5}\right.$ cells $)$ or 6 well microtiter plates $\left(2 \times 10^{6}\right.$ cells $)$ and immediately treated with mitogen (concanavalin A; $0.63 \mu \mathrm{g} / \mathrm{mL}$ ) and CI-994 (1,3, 10 , or $30 \mu \mathrm{M})$. The cells were then incubated for 4 or 24 hours at $37^{\circ} \mathrm{C}$ in $5 \% \mathrm{CO}_{2}$. An equivalent volume of vehicle (distilled water) was added to the untreated (control) lymphocytes. The amount of ethanol in the CI-994 solutions was less than $1 \%(\mathrm{v} / \mathrm{v})$. Concanavalin A was added to the culture media in the present study since preliminary experiments showed that it had a protective effect on untreated lymphocytes by significantly reducing the spontaneous incidence of apoptosis. Supplemental assays were also performed to determine the effect of CI-994 on nonproliferating lymphocytes. For these latter assays, lymphocytes were incubated with CI-994 (1 and $30 \mu \mathrm{M})$ for 24 hours without mitogen.

\section{Lymphocyte proliferation}

Lymphocyte proliferation was determined by the addition of $0.5 \mu \mathrm{Ci}$ of $\left[{ }^{3} \mathrm{H}\right]$ thymidine to each well in a 96-well plate according to the assay conditions described above. $\left[{ }^{3} \mathrm{H}\right]$ Thymidine was added at the time of assay initiation. The amount of $\left[{ }^{3} \mathrm{H}\right]$ thymidine incorporated into lymphocyte DNA was counted by liquid scintillation spectroscopy. Four separate lymphocyte proliferation assays were performed.

\section{Fluorescent microscopy}

Lymphocytes were collected and immediately incubated with $100 \mu \mathrm{g} / \mathrm{ml}$ acridine orange and $100 \mu \mathrm{g} / \mathrm{ml}$ ethidium bromide (in PBS) to visualize apoptotic cells. For quantitative analysis, cells were viewed with an Olympus AH-3 microscope at $40 \times$ using FITC filter sets to excite $(488 \mathrm{~nm})$ and visualize $(530 \mathrm{~nm})$ stains. Cells containing stained pycnotic nuclei (DNA condensation) were considered apoptotic. Staining and scoring procedures followed those described in McGahon et al. [21]. Two to four hundred cells were counted per treatment, and measurements were obtained from at least four independent experiments. For image capture, cells were stained for DNA using Hoechst 33342 (Molecular Probes, Eugene, OR) and mounted on standard microscope slides. Images were captured using a $100 \times$ objective with a high-resolution, liquid-cooled CCD camera (Quantix, RS-Photometrics, 
Tucson, AZ) mounted on an inverted fluorescence microscope (Axiovert 135, Zeiss, New York, NY). Illumination was provided by a 100 watt mercury lamp using a DAPI dichroic filter set (Chroma Technology, Brattleboro, VT).

\section{Electron microscopy}

Approximately $1-2 \times 10^{6}$ cells were fixed in $2.5 \%$ glutaraldehyde (Polysciences, Warrington, PA) for $1 \mathrm{~h}$. Cells were then collected by centrifugation and rinsed three times in 0.1 M cacodylate buffer, $\mathrm{pH}$ 7.4. Cells were osmicated for approximately $1 \mathrm{~h}$, rinsed three times in cacodylate buffer, then dehydrated and embedded in epoxy resin. Ultrathin sections were examined using an FEI Philips CM100 BioTWIN transmission electron microscope.

\section{Flow cytometric analysis of DNA content}

Lymphocytes were collected and fixed in 70\% ethanol for at least 30 minutes. Fixed cells were then stained with $5 \mu \mathrm{g} / \mathrm{ml}$ Hoechst 33342 to detect total DNA within cells [22]. Samples were collected on a Coulter Epics Elite flow cytometer, and data were analyzed and quantitated using Modfit $L T$ software (Verity Software House, Inc.). Cells with sub-G1 DNA content were considered to be apoptotic. At least four independent experiments were performed.

\section{DNA fragmentation assay}

DNA was isolated from lymphocytes using the apoptotic DNA-Ladder kit (Boehringer Mannheim, Indianapolis, IN). Isolated DNA was quantitated spectrophotometrically using Softmax Pro 2.4.1 software (Molecular Dynamics, Sunnyvale, CA). DNA $(0.6 \mu \mathrm{g})$ was separated by electrophoresis on a $1 \%$ agarose gel stained with ethidium bromide for visualization. Results were confirmed by three independent experiments.

\section{Flow cytometric analysis of phosphatidyl serine externalization}

Lymphocytes were collected and immediately incubated with annexin V-FITC, which binds to phosphatidyl serine (PS) present on the outer cellular membrane. Staining was performed using Annexin V-FITC Apoptosis Detection Kit purchased from Oncogene Research Products (Cambridge, MA). Procedures followed the manufacturer's instructions. Propidium iodide stain was included for differentiating viable and nonviable (late apoptotic/necrotic) cells. Samples were collected using the Coulter Epics Elite flow cytometer, and data were analyzed and quantitated using Winlist 4.0 software (Verity Software House, Inc.). Cells with increased green staining due to the binding of annexin V-FITC to PS were categorized as apoptotic. At least four independent experiments were performed.

\section{Lactate dehydrogenase (LDH) release assay}

Lymphocytes were evaluated for the presence of necrotic cell death by measuring LDH release from cells into the cul- ture medium. LDH release was detected using the CytoTox $96{ }^{\circledR}$ Non-Radioactive Cytotoxicity Assay (Promega). Procedures followed manufacturer's instructions. Data were collected from three independent experiments.

\section{Statistical analysis}

Statistical analysis was performed using SigmaStat 2.03 software (SciTech International, Inc., Chicago, IL). Differences with $p$ values less than 0.05 were considered statistically significant.

\section{RESULTS}

\section{Lymphocyte proliferation}

The number of proliferating lymphocytes in the presence of concanavalin A was $1 \%$ and $4 \%$ after 4 hours and 24 hours of incubation, respectively.

\section{Morphological changes}

There was no significant increase in the number of apoptotic cells detected by fluorescent microscopy after 4 hours of exposure to CI-994 (Figure 2). After 24 hours of exposure, the number of apoptotic lymphocytes at 10 and $30 \mu \mathrm{M}$ CI-994 was significantly increased relative to the untreated controls: $79 \%$ at 10 and $30 \mu \mathrm{M} \mathrm{CI-994} \mathrm{versus} 16 \%$ in the controls (Figure 2). Although not statistically significant, the percentage of apoptotic cells was also increased at 1 and $3 \mu \mathrm{M}$ CI-994: $28 \%$ and 34\%, respectively. For lymphocytes incubated without mitogen, the percentage of apoptotic cells were $12 \%, 15 \%$, and $51 \%$, at CI-994 concentrations of 0,1 , and $30 \mu \mathrm{M}$, respectively. Condensed chromatin, apoptotic bodies, and membrane blebbing were characteristic of apoptotic cells (Figure 3). Ultrastructural examination of rat lymphocytes exposed to $30 \mu \mathrm{M}$ CI-994 for 24 hours also showed typical morphological features of apoptosis including chromatin condensation and fragmentation, membrane blebbing, and cell shrinkage (Figure 4).

\section{DNA fragmentation}

Apoptotic cells fixed and permeabilized in ethanol lose fragmented DNA resulting in DNA histograms with a subG1 DNA content [23-25]. No significant increase in sub-G1 cells was detected in rat lymphocytes treated with CI-994 for 4 hours when analyzed by flow cytometry and Hoechst 33352 stain (Figure 5). However, exposure to CI-994 for 24 hours led to a dose-related increase in the number of sub-G1 cells relative to the untreated controls (Figure 5). The increase in subG1 cells was statistically significant at $30 \mu \mathrm{M}$ CI-994. Without mitogen, the percentage of apoptotic cells detected by flow cytometry and Hoechst 33352 stain were 18\%, 15\%, and 55\%, at CI-994 concentrations of 0,1 , and $30 \mu \mathrm{M}$, respectively. A distinct DNA fragmentation pattern consisting of multiples of $180 \mathrm{bp}$ was also observed in rat lymphocytes exposed to CI-994 for 24 hours when analyzed by gel electrophoresis 


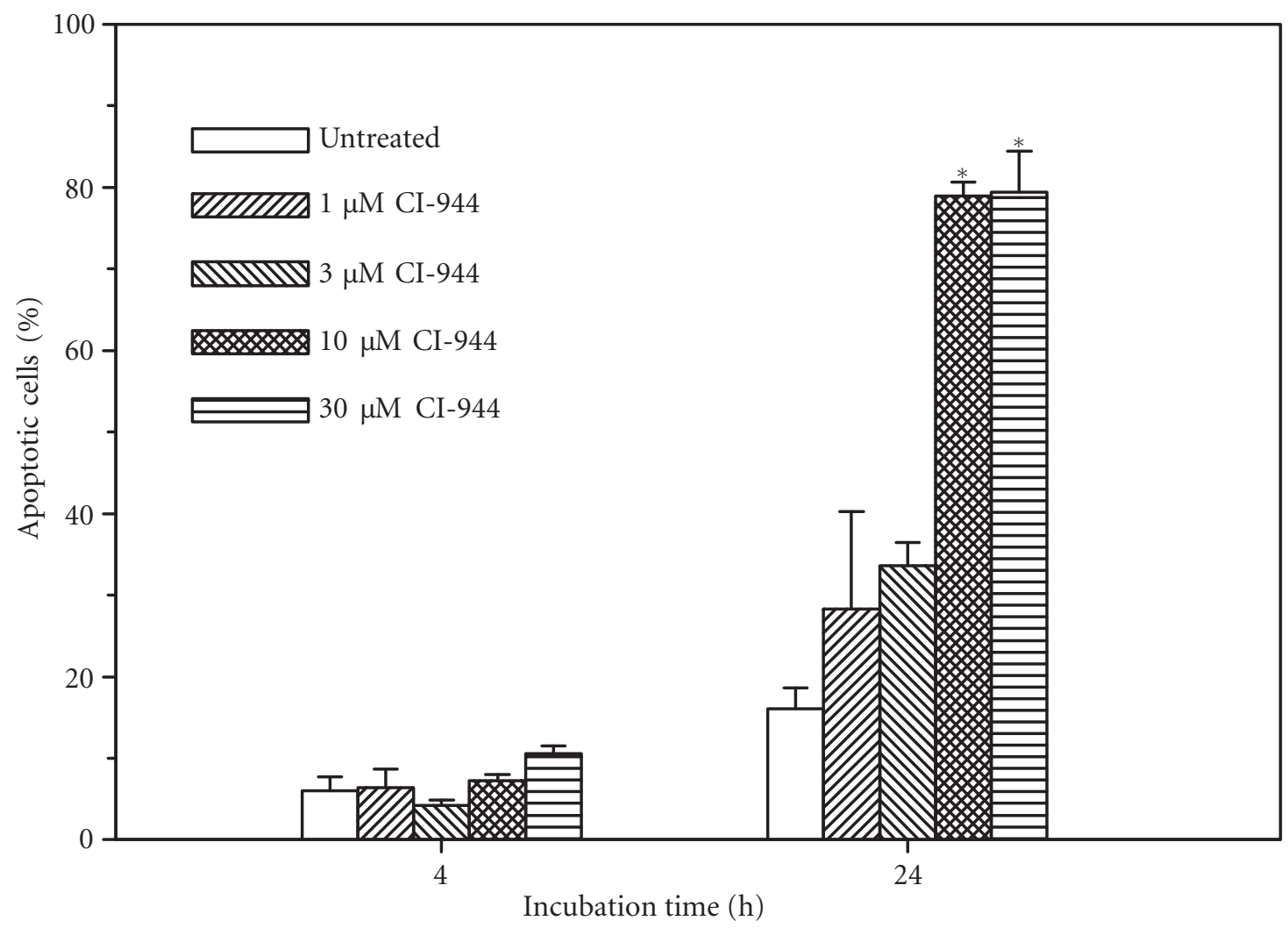

FIGURE 2: Apoptosis in rat peripheral blood lymphocytes exposed to CI-994 for 4 or 24 hours. Mitogen (concanavalin A, $0.63 \mu \mathrm{g} / \mathrm{ml}$ ) was added to all lymphocyte cultures at time zero. Apoptotic cells characterized by condensed DNA were visualized by fluorescent microscopy and acridine orange/ethidium bromide stain. Data represent the mean $\pm \mathrm{SE}$ of at least 4 individual experiments.

* Significantly different from control using Kruskal-Wallis one way ANOVA on ranked data and Dunn's post hoc test $(p<0.05)$.

(Figure 6). DNA fragmentation was evident at CI-994 concentrations as low as $3 \mu \mathrm{M}$ with a dose-related increase in band intensity.

\section{Membrane changes}

A biochemical marker of apoptosis that does not involve changes in DNA is redistribution of PS from the inner leaflet to the outer leaflet of the cellular membrane [26, 27]. Using the binding of fluorescein isothiocyanate (FITC)-labeled annexin $\mathrm{V}$ to externalized PS, apoptotic cells can be quantitated by flow cytometry $[27,28]$. There was no significant increase in the percent of lymphocytes exhibiting externalization of PS after 4 hours of exposure to CI-994 (Figure 7). After 24 hours of incubation, rat lymphocytes treated with $30 \mu \mathrm{M}$ CI-994 showed a significant increase in externalization of PS relative to untreated controls (Figure 7). Although not statistically significant, the number of lymphocytes exhibiting PS externalization also appeared to be increased at $10 \mu \mathrm{m}$ CI-994.

\section{Necrotic cell death}

No significant increase in $\mathrm{LDH}$ release was detected in the culture medium of any of the treatment groups after 4 hours of exposure to CI-994. After 24 hours of incubation,
TABLE 1: LDH release from rat peripheral blood lymphocytes treated with CI-994.

\begin{tabular}{lcc}
\hline \multirow{2}{*}{ Treatment group } & \multicolumn{2}{c}{ Percent of maximum LDH release } \\
\cline { 2 - 3 } & $4 \mathrm{~h}$ incubation & $24 \mathrm{~h}$ incubation \\
\hline Untreated & $0.0 \pm 0.0$ & $0.0 \pm 0.0$ \\
\hline $1 \mu \mathrm{M}$ CI-994 & $0.0 \pm 1.0$ & $0.0 \pm 1.3$ \\
\hline $3 \mu \mathrm{M}$ CI-994 & $0.0 \pm 0.4$ & $0.4 \pm 1.9$ \\
\hline $10 \mu \mathrm{M}$ CI-994 & $1.6 \pm 0.9$ & $7.0 \pm 2.2^{*}$ \\
\hline $30 \mu \mathrm{M}$ CI-994 & $2.0 \pm 0.7$ & $15.1 \pm 3.5^{*}$ \\
\hline Positive control $^{b}$ & $111.5 \pm 13.6^{*}$ & $129.9 \pm 14.8^{*}$ \\
\hline
\end{tabular}

${ }^{a}$ Values are means $\pm \mathrm{SE}, n=3$.

${ }^{b}$ Positive control $=$ NP40 cell lysis buffer.

* Significantly different from control using Kruskal-Wallis one way ANOVA on ranked data and Dunn's post hoc test $(p<0.05)$.

a significant increase in LDH release above control levels was detected in the medium from lymphocytes treated with 10 and $30 \mu \mathrm{M}$ CI-994 (Table 1). For these two treatments, the percent of maximum $\mathrm{LDH}$ release was $7 \%$ and $15 \%$, respectively, compared with $0 \%$ in the controls. 

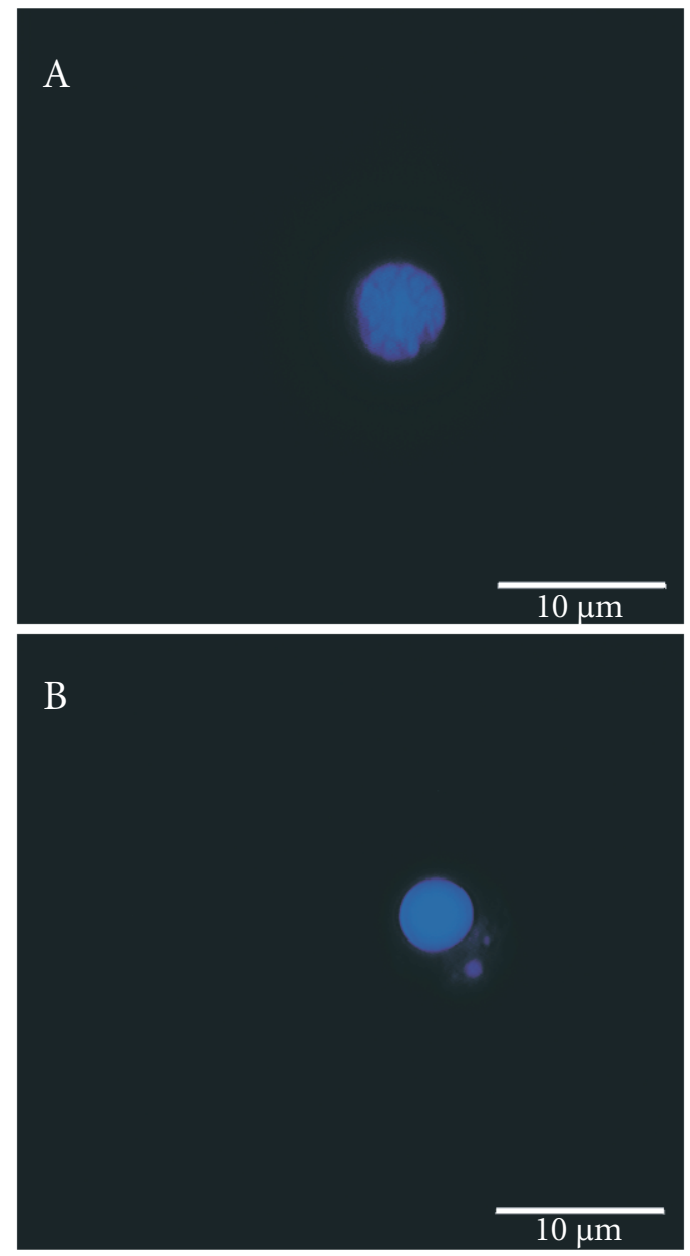

FIGURE 3: Fluorescent staining of (A) untreated rat peripheral blood lymphocyte and (B) rat peripheral blood lymphocyte exposed to $30 \mu \mathrm{M}$ CI-994 for 24 hours. Mitogen (concanavalin A, $0.63 \mu \mathrm{g} / \mathrm{ml}$ ) was added to all lymphocyte cultures at time zero. Morphological changes typical of apoptosis including condensed chromatin, apoptotic body, and membrane blebbing are apparent in treated lymphocyte.

\section{DISCUSSION}

Apoptosis is a common mechanism of cell death that is characterized by chromatin condensation, DNA fragmentation, membrane blebbing, and cell shrinkage without altered permeability of the plasma membrane [14-18, 21, 29-32]. In contrast to apoptosis, necrosis is characterized by organelle and cell swelling, loss of membrane integrity, rupture of the plasma membrane, and cell lysis. In the present study, several different techniques were used to assess apoptosis and necrosis in rat peripheral blood lymphocytes exposed to CI-994. Based on changes in cell morphology, a dose-related trend of increased apoptosis was observed at all CI-994 concentrations. The effects at 10 and $30 \mu \mathrm{M} \mathrm{CI}-994$ were statistically significant. At these latter concentrations, almost $80 \%$ of lymphocytes were undergoing apoptosis after 24 hours. In com-

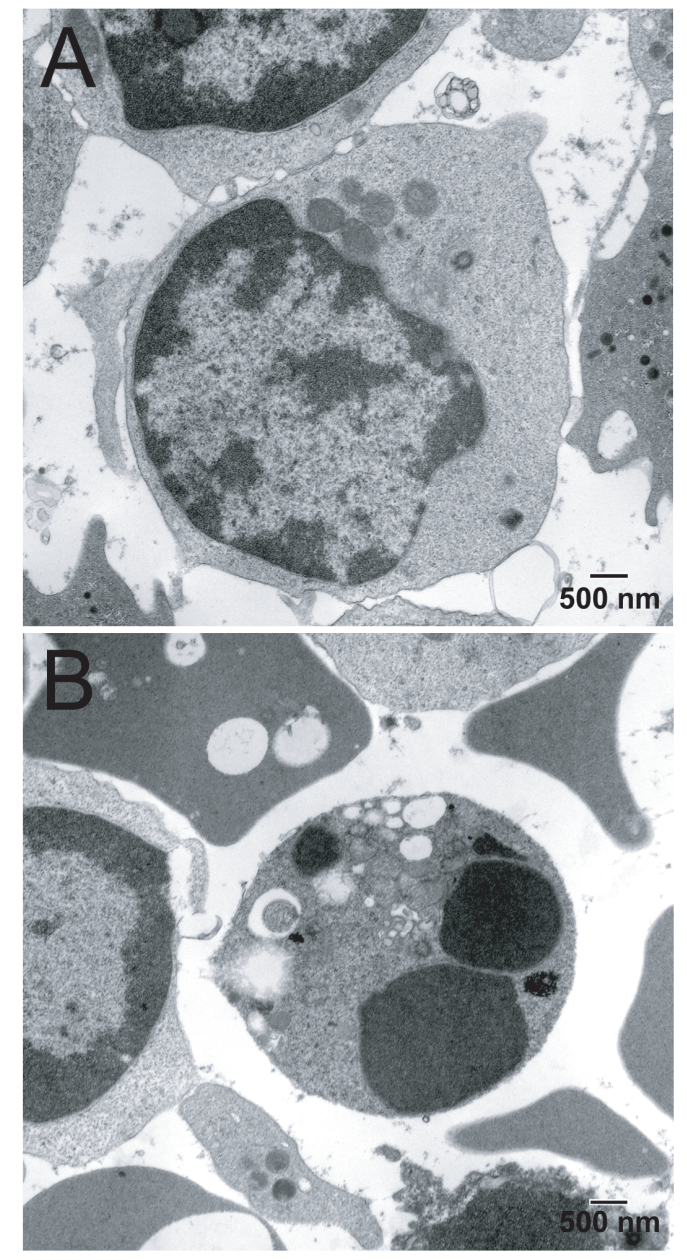

FIGURE 4: Electron micrograph of (A) untreated rat peripheral blood lymphocyte and (B) rat peripheral blood lymphocyte exposed to $30 \mu \mathrm{M}$ CI-994 for 24 hours. Mitogen (concanavalin A, $0.63 \mu \mathrm{g} / \mathrm{ml}$ ) was added to all lymphocyte cultures at time zero. Treated lymphocyte shows morphological changes of apoptosis including chromatin condensation and fragmentation, membrane blebbing, and cell shrinkage.

parison, less than $15 \%$ of lymphocytes treated with $30 \mu \mathrm{M}$ CI-994 were undergoing necrosis based on release of LDH. These results demonstrate that necrosis plays little if any role in the toxicity of CI-994 and that apoptosis is the primary mechanism of cell death.

The ability of CI-994 to induce apoptosis in peripheral blood lymphocytes within 24 hours in vitro is consistent with the in vivo effects produced by this drug. Specifically, administration of CI-994 to male rats caused significant reductions in lymphoid tissue, bone marrow myeloid, and lymphoid cells, and peripheral blood lymphocytes, monocytes, and neutrophils within 24 hours of a single oral dose [11]. Furthermore, CI-994 concentrations used in vitro were in the same range as plasma and cerebrospinal fluid concentrations of CI-994 achieved in vivo in preclinical and clinical studies $[10,13,33]$. Collectively, these results demonstrate 

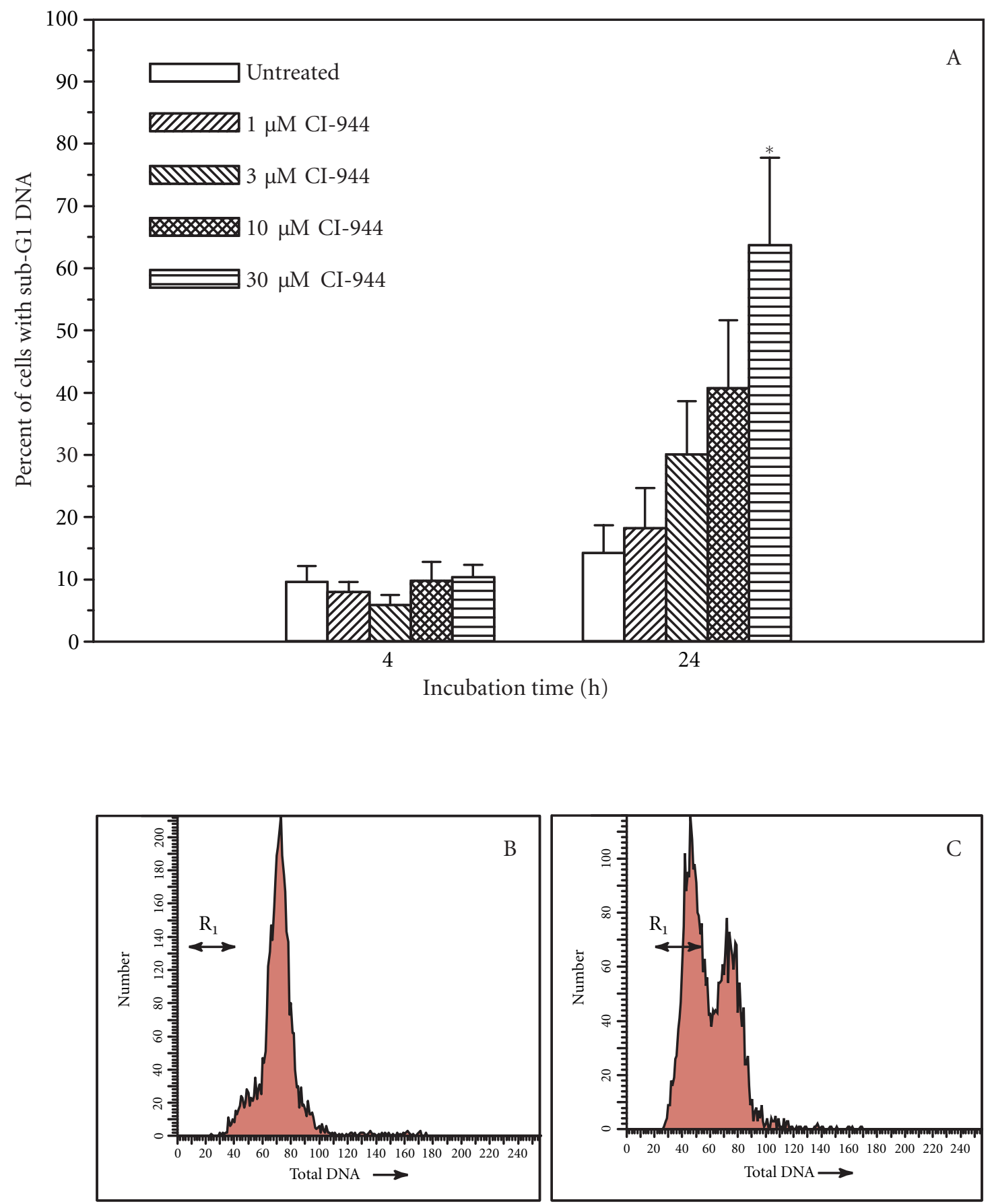

Total DNA

Figure 5: Sub-G1 DNA content in rat peripheral blood lymphocytes exposed to CI-994 for 4 or 24 hours. (A) Sub-G1 DNA content quantitated by flow cytometry and Hoechst 33342 stain. Mitogen (concanavalin A, $0.63 \mu \mathrm{g} / \mathrm{ml}$ ) was added to all lymphocyte cultures at time zero. Data represent the mean \pm SE of at least 4 individual experiments. *Significantly different from control using Kruskal-Wallis one way ANOVA on ranked data and Dunn's post hoc test $(p<0.05)$. Representative DNA histograms of (B) untreated rat peripheral blood lymphocytes and (C) lymphocytes treated with $30 \mu \mathrm{M}$ CI-994 for 24 hours. $\mathrm{R}_{1}$ = gated sub-G1 DNA population. 


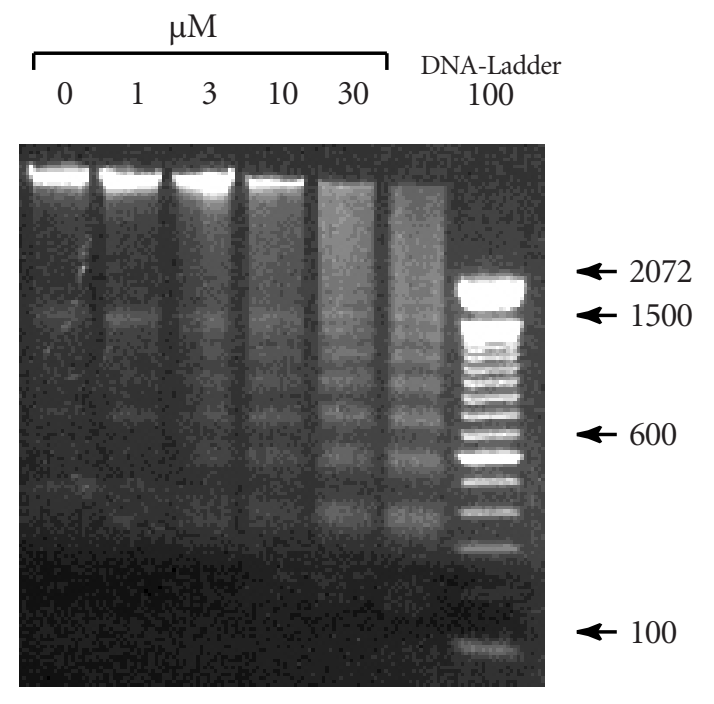

FIGURE 6: DNA fragmentation in rat peripheral blood lymphocytes exposed to CI-994 for 24 hours. Mitogen (concanavalin A, $0.63 \mu \mathrm{g} / \mathrm{ml}$ ) was added to all lymphocyte cultures at time zero. DNA $(0.6 \mu \mathrm{g})$ was separated on a $1 \%$ agarose gel stained with ethidium bromide. Arrows indicate molecular weight markers. Positive control $=1 \mu \mathrm{M}$ staurosporine (lane 6).

that peripheral rat blood lymphocytes represent a toxicologically relevant model for studying the mechanism of CI-994 toxicity in vitro.

Concanavalin A was added to the culture media in the present study since preliminary experiments showed that it had a protective effect on untreated lymphocytes by significantly reducing the spontaneous incidence of apoptosis. However, even with the addition of concanavalin A, litthe if any proliferation occurred over 24 hours $(\leq 4 \%)$. This observation is consistent with a reported $24-28$ hours delay in cell division in rat lymphocytes in culture with concanavalin A [34], and suggests that the induction of apoptosis by CI-994 occurred independently of cell proliferation. The ability of CI-994 to induce apoptosis in nonproliferating lymphocytes was confirmed by the results of several supplemental assays in which mitogen was omitted from the incubation mixture. The apoptotic effects of CI-994 on nonproliferating lymphocytes is similar to that of topoisomerase inhibitors and opposite of cisplatin and 2-chloro-2' deoxyadenosine, the latter of which appear to only induce apoptosis in dividing cells [35-38]. The effect of CI-994 on nonproliferating cells is also consistent with the rapid loss of peripheral blood lymphocytes following CI-994 administration in vivo [11]. The majority of circulating lymphocytes are considered long-lived and do not proliferate in the absence of antigenic stimulation [39-41]. Therefore, apoptotic cell death is one possible mechanism by which circulating lymphocytes may be depleted during in vivo exposure to CI994.

Apoptosis induced by CI-994 does not occur as rapidly as with other cytotoxic anticancer drugs. In the present study, no apoptosis was observed in lymphocytes after 4 hours of exposure to CI-994. In contrast, a variety of anticancer drugs, including topoisomerase inhibitors such as etoposide and camptothecin, can induce apoptosis in mouse and rat thymocytes and in human HL60 leukemia cells within 2 to 4 hours of incubation [38, 42-45]. Whether the delayed effects of CI-994 are due to different experimental conditions (e.g., use of rat lymphocytes in the present study) or differences related to the mechanism of action of CI-994 is unknown. Nonetheless, these results correlate with the inhibitory effect of CI-994 on cell cycle progression prior to the appearance of cytotoxicity in vitro [46].

Although the mechanism of action of CI-994 has not yet been defined, it may be the same in both tumor cells and normal tissue since CI-994 was also shown to induce apoptosis in HL60 leukemia cells [47]. The mechanism of apoptosis was not investigated in this study but previous reports suggest that it may be initiated by either inhibition of a $16 \mathrm{kDa}$ nuclear phosphoprotein or an increase in histone acetylation $[8,9]$. In both studies, these targets were modulated within 2 hours of exposure and thus represent the earliest effects detected following CI-994 treatment in vitro. Whether inhibition of the $16 \mathrm{kDa}$ nuclear phosphoprotein or an increase in histone acetylation is the initiating event leading to cell death induced by CI-994 has not been established. In HL60 cells, CI-994-induced apoptosis involves activation of caspase- 3 and cleavage of poly(ADP-ribose) polymerase [47]. Since caspase- 3 is a downstream effector caspase, it is possible that other caspases may also be involved in CI-994-induced apoptosis.

Levels of PARP, which can recognize and bind to DNA strand-breaks [48, 49], appeared to be increased in HL60 cells following exposure to $3 \mu \mathrm{M}$ CI-994 [47]. It is not known whether this latter observation is indicative of DNA damage at low concentrations of CI-994 or represents a characteristic burst in PARP activity early in the apoptotic process [50]. The precise role of DNA damage in CI-994 cytotoxicity has not been completely investigated but in vitro studies with the deacetylated analogue, dinaline, showed that cytotoxicity in L1210 leukemia cells could not be reversed by purines, pyrimidines, or reduced folates [51]. There were also no direct effects on ribonucleotide phosphate pools or DNA, RNA, or lipid synthesis. Since dinaline and CI-994 have equivalent antitumor activity $[1,4,46]$, these results suggest that CI994 does not act as an antimetabolite, nor does it directly effect macromolecular synthesis. However, inhibition of CI-994 and dinaline on DNA synthesis measured by $\left[{ }^{3} \mathrm{H}\right]$ thymidine incorporation has been observed in rat peripheral blood lymphocytes and human colon carcinoma SW707 cells [11, 52].

In summary, CI-994 induced apoptosis in rat peripheral blood lymphocytes in a concentration-dependent manner. Apoptosis was confirmed by morphological and biochemical changes including membrane blebbing, chromatin condensation, DNA fragmentation, and externalization of PS. Necrosis was not detected to any significant extent. These results show that apoptosis is the primary mode of cell death in rat lymphocytes exposed to CI-994 in vitro. 

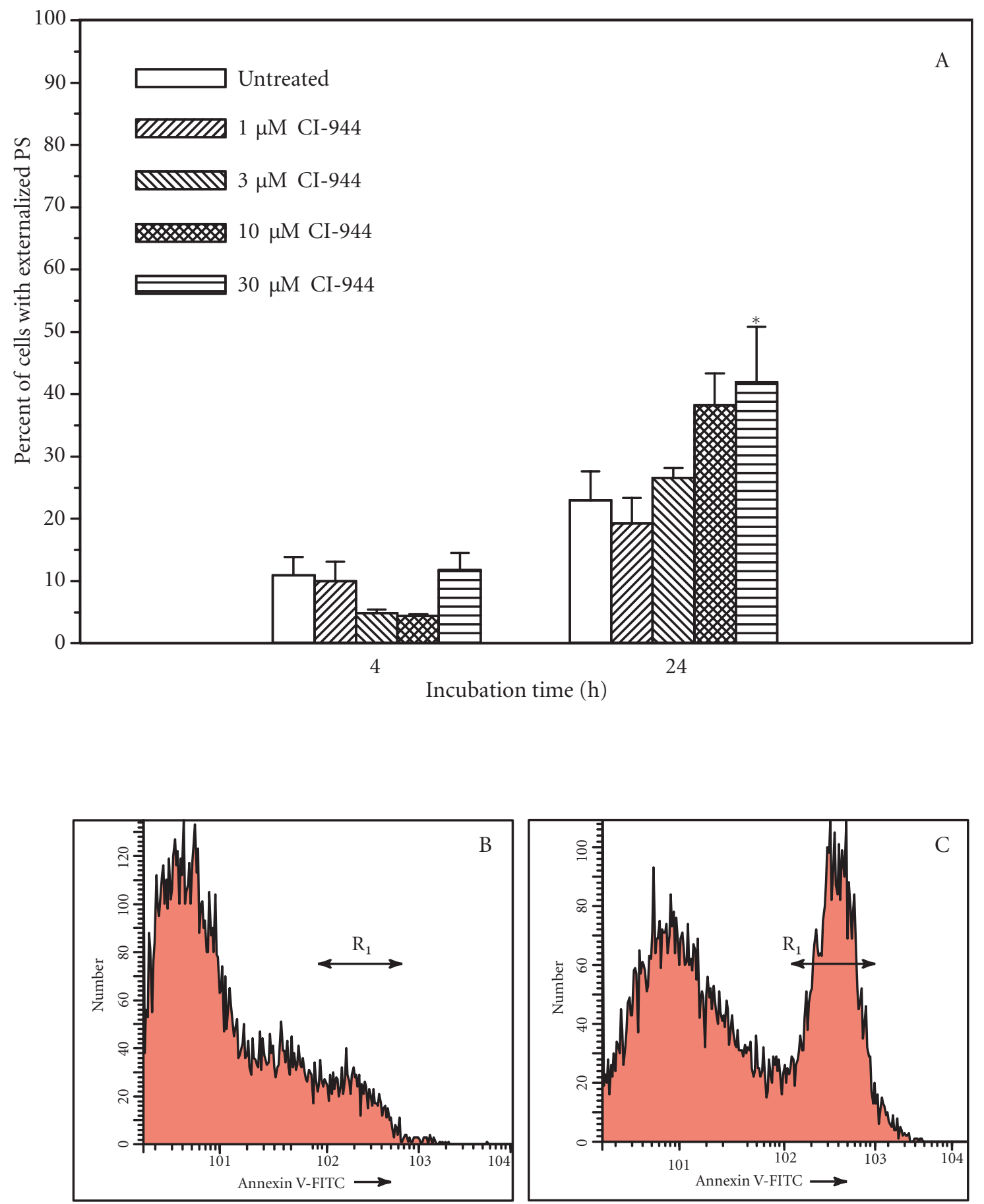

Annexin V-FITC

FIGURE 7: Externalization of phosphatidyl serine (PS) in rat peripheral blood lymphocytes exposed to CI-994 for 4 or 24 hours. (A) Externalized PS in the cellular membrane was detected by flow cytometry and annexin V-FITC stain. Mitogen (concanavalin A, $0.63 \mu \mathrm{g} / \mathrm{ml}) \mathrm{was}$ added to all lymphocyte cultures at time zero. Data represent the mean \pm SE of at least 4 individual experiments. ${ }^{*}$ Significantly different from control using one way ANOVA and a Tukey post hoc test $(p<0.05)$. Representative PS histograms of $(\mathrm{B})$ untreated rat peripheral blood lymphocytes and (C) lymphocytes treated with $30 \mu \mathrm{M}$ CI-994 for 24 hours. $\mathrm{R}_{1}=$ gated annexin V-FITC population. 


\section{ACKNOWLEDGMENTS}

The authors thank Gregg Sobocinski for technical assistance with electron microscopy and Dr Jeff Haskins for capturing the fluorescent microscopy images.

\section{REFERENCES}

[1] Berger MR, Richter H, Seelig MH, Eibl H, Schmähl D. New cytostatics-more activity and less toxicity. Cancer Treat Rev. 1990;17:143-154.

[2] El-Beltagi HM, Martens ACM, Dahab GM, Hagenbeek A. Efficacy of acetyldinaline for treatment of minimal residual disease (MRD): preclinical studies in the BNML rat model for human acute myelocytic leukemia. Leukemia. 1993;7:1795-1800.

[3] El-Beltagi HM, Martens ACM, Lelieveld P, Haroun EA, Hagenbeek A. Acetyldinaline: a new oral cytostatic drug with impressive differential activity against leukemic cells and normal stem cells-preclinical studies in a relevant rat model for human acute myelocytic leukemia. Cancer Res. 1993;53:3008-3014.

[4] Howard CT, Roberts BJ, Vincent PW, Elliot WL. Nacetyldinaline: a small molecule with in vivo cytostatic activity. Proc Am Assoc Cancer Res. 1992;33:393.

[5] LoRusso PM, Demchik L, Foster B, et al. Preclinical antitumor activity of CI-994. Invest New Drugs. 1996;14:349-356.

[6] Howard CT, Guisbert EA, Schaefer JS, Merriman RL. In vivo antitumor activity of CI-994 ( N-acetyl-dinaline, GOE 5549) alone and in combination with gemcitabine against LC12 squamous cell lung carcinoma. Proc Am Assoc Cancer Res. 1999;40:590.

[7] Grabow D, Graziano M, Grove W, Merriman R, Morosky S, Olson S. Investigator's Brochure: CI-994. ParkeDavis Pharmaceutical Research, Division of WarnerLambert;1999.

[8] Rummel SA, Kraker AJ, Steinkampf RW, Hook KE, Klohs WD. Role of a small molecular weight phosphoprotein in the mechanism of action of CI-994 (Nacetyldinaline). Int J Cancer. 1995;62:636-642.

[9] Kraker AJ, Hartl BG, Miin J, Merriman RL. Effect of CI-994 (N-acetyldinaline or 4-(acetylamino)-N-(2aminophenyl) benzamide) on histone acetylation and differentiation in HCT-8 colon carcinoma cells. Proc Am Assoc Cancer Res. 1999;40:121.

[10] Graziano MJ, Pilcher GD, Walsh KM, Kasali OB, Radulovic L. Preclinical toxicity of a new oral anticancer drug, CI-994 (acetyldinaline), in rats and dogs. Invest New Drugs. 1997;15:295-310.

[11] Graziano MJ, Galati AJ, Walsh KM. Immunotoxicity of the anticancer drug CI-994 in rats: effects on lymphoid tissue. Arch Toxicol. 1999;73:168-174.

[12] Foster BJ, Jones L, Wiegand R, LoRusso PM, Corbett TH. Preclinical pharmacokinetic, antitumor and toxicity studies with CI-994 (N-acetyldinaline). Invest New Drugs. 1997;15:187-194.
[13] LoRusso PM, Wozniak A, Foster B, et al. Phase I clinical trial of CI-994. Proc Am Soc Clin Oncol. 1997;16:213a.

[14] Alison MR, Sarraf CE. Apoptosis: regulation and relevance to toxicology. Hum Exp Toxicol. 1995;14:234-247.

[15] Corcoran GB, Fix L, Jones DP, Moslen MT, Nicotera P, Oberhammer FA, Buttyan R. Apoptosis: molecular control point in toxicology. Toxicol Appl Pharmacol. 1994;128:169-181.

[16] Dive C, Gregory CD, Phipps DJ, Evans DL, Milner AE, Wyllie AH. Analysis and discrimination of necrosis and apoptosis (programmed cell death) by multiparameter flow cytometry. Biochim Biophys Acta. 1992;1133:275285.

[17] Fawthrop DJ, Boobis AR, Davies DS. Mechanisms of cell death. Arch Toxicol. 1991;65:437-444.

[18] Kerr JFR, Wyllie AH, Currie AR. Apoptosis: a basic biological phenomenon with wide-ranging implications in tissue kinetics. Br J Cancer. 1972;26:239-257.

[19] Renvoizé C, Biola A, Pallardy M, Bréard J. Apoptosis: identification of dying cells. Cell Biol Toxicol. 1998;14:111-120.

[20] National Research Council. Guide for the care and use of laboratory animals. National Academy Press;1996.

[21] McGahon AJ, Martin SJ, Bissonnette RP, Mahboubi A, Shi Y, Mogil RJ, Nishioka WK, Green DR. The end of the (cell) line: methods for the study of apoptosis in vitro. Methods Cell Biol. 1995;46:153-185.

[22] Darzynkiewicz Z, Li X, Gong J. Assays of cell viability: discrimination of cells dying by apoptosis. Methods Cell Biol. 1994;41:15-38.

[23] Afanasyev VN, Korol BA, Matylevich NP, Pechatnikov VA, Umansky SR. The use of flow cytometry for the investigation of cell death. Cytometry. 1993;14: 603-609.

[24] Darzynkiewicz Z, Bruno S, Del Bino G, et al. Features of apoptotic cells measured by flow cytometry. Cytometry. 1992;13:795-808.

[25] Nicoletti I, Migliorati G, Pagliacci MC, Grignani F, Riccardi C. A rapid and simple method for measuring thymocyte apoptosis by propidium iodide staining and flow cytometry. J Immunol Methods. 1991;139:271-279.

[26] Fadok VA, Voelker DR, Campbell PA, Cohen JJ, Bratton DL, Henson PM. Exposure of phosphatidylserine on the surface of apoptotic lymphocytes triggers specific recognition and removal by macrophages. J Immunol. 1992;148:2207-2216.

[27] Martin SJ, Reutelingsperger CPM, McGahon AJ, Radar JA, van Schie RCAA, LaFace DM, Green DR. Early redistribution of plasma membrane phosphatidylserine is a general feature of apoptosis regardless of the initiating stimulus: inhibition by overexpression of Bcl-2 and Abl. J Exp Med. 1995;182:1545-1556.

[28] Koopman G, Reutelingsperger CPM, Kuijten GAM, Keehnen RMJ, Pals ST, van Oers MHJ. Annexin V for flow cytometric detection of phosphatidylserine expression on B cells undergoing apoptosis. Blood. 1994;84:1415-1420. 
[29] Compton MM. A biochemical hallmark of apoptosis: internucleosomal degradation of the genome. Cancer Metastasis Rev. 1992;11:105-119.

[30] Eastman A. Apoptosis: a product of programmed and unprogrammed cell death. Toxicol Appl Pharmacol. 1993;121:160-164.

[31] Hickman JA. Apoptosis induced by anticancer drugs. Cancer Metastasis Rev. 1992;11:121-139.

[32] Wyllie AH, Morris RG, Smith AL, Dunlop D. Chromatin cleavage in apoptosis: association with condensed chromatin morphology and dependence on macromolecular synthesis. J Pathol. 1984;142:67-77.

[33] Riva L, Blaney SM, McGuffey SM, Berg SL. Pharmacokinetics and cerebrospinal fluid penetration of CI-994 (N-acetyldinaline) in the nonhuman primate. Proc Am Assoc Cancer Res. 1999;40:388.

[34] Guzzie PJ, Oshiro Y. An optimized procedure for cultivating rat lymphocytes for in vitro cytogenetic screening. Environ Mol Mutagenesis. 1989;14(suppl 15):80.

[35] Evans DL, Dive C. Effects of cisplatin on the induction of apoptosis in proliferating hepatoma cells and nonproliferating immature thymocytes. Cancer Res. 1993;53:2133-2139.

[36] Evans DL, Tilby M, Dive C. Differential sensitivity to the induction of apoptosis by cisplatin in proliferating and quiescent immature rat thymocytes is independent of the levels of drug accumulation and DNA adduct formation. Cancer Res. 1994;54:1596-1603.

[37] Lassota P, Kazimierczuk Z, Darzynkiewicz Z. Apoptotic death of lymphocytes upon treatment with 2-chloro2'-deoxyadenosine (2-Cda). Arch Immunol Ther Exp. 1994;42:17-23.

[38] Walker PR, Smith C, Youdale T, Leblanc J, Whitfield JF, Sikorska M. Topoisomerase II-reactive chemotherapeutic drugs induce apoptosis in thymocytes. Cancer Res. 1991;51:1078-1085.

[39] Everett NB, Caffrey RW, Rieke WO. Recirculation of lymphocytes. Ann NY Acad Sci. 1964;113:887-897.

[40] Robinson SH, Brecher G, Lourie IS, Haley JE. Leukocyte labeling in rats during and after continuous infusion of tritiated thymidine: implications for lymphocyte longevity and DNA reutilization. Blood. 1965;26:281295.

[41] Sprent J, Tough DF. Lymphocyte life-span and memory. Science. 1994;265:1395-1400.

[42] Gorczyca W, Gong J, Ardelt B, Traganos F, Darzynkiewicz $Z$. The cell cycle related differences in susceptibility of HL-60 cells to apoptosis induced by various antitumor agents. Cancer Res. 1993;53:3186-3192.

[43] Kaufmann SH. Induction of endonucleolytic DNA cleavage in human acute myelogenous leukemia cells by etoposide, camptothecin, and other cytotoxic anticancer drugs: a cautionary note. Cancer Res. 1989;49:58705878.

[44] OnishiY, Azuma Y, Sato Y, Mizuno Y, Tadakuma T, Kizaki $\mathrm{H}$. Topoisomerase inhibitors induce apoptosis in thymocytes. Biochim Biophys Acta. 1993;1175:147-154.

[45] Sun XM, Snowden RT, Dinsdale D, Ormerod MG, Cohen GM. Changes in nuclear chromatin precede internucleosomal DNA cleavage in the induction of apoptosis by etoposide. Biochem Pharmacol. 1994;47:187-195.

[46] Kraker AJ, Wolven A, Fry DW, Klohs WD. Cell cycle and nucleotide effects of 4-(acetylamino)-N-(2aminophenyl)benzamide (PD 123654, Goe 5549) in HCT-8 cells. Proc Am Assoc Cancer Res. 1991;32:396.

[47] Padalino TA, Cockrell EA, Gonzales AJ, Graziano MJ. Characterization of CI-994 induced apoptosis in human leukemia (HL60) cells. Toxicol Sci. 1999;48(1-S):152.

[48] Benjamin RC, Gill DM. Poly(ADP-ribose) synthesis in vitro programmed by damaged DNA. J Biol Chem. 1980;255:10502-10508.

[49] Kaufman SH, Desnoyers S, Ottaviano S, Davidson NE, Poirier GG. Specific proteolytic cleavage of poly(ADPribose) polymerase: an early marker of chemotherapyinduced apoptosis. Cancer Res. 1993;53:3976-3985.

[50] Simbulan-Rosenthal CM, Rosenthal DS, Iyer SI, Boulares AH, Smulson ME. Transient poly(ADPribosyl)ation of nuclear proteins and role of poly(ADPribose) polymerase in the early stages of apoptosis. J Biol Chem. 1998;22:13703-13712.

[51] Leopold WR, Hook KE, Fry DW. Activity and biochemical properties of Goe 1734 (PD 104208), an anticancer agent with a novel mechanism of activity. Proc Am Assoc Cancer Res. 1987;28:302.

[52] Schaider H, Haberkorn U, Stöhr M, Berger MR. Dinaline inhibits amino acid transport and proliferation of colon carcinoma cells in vitro. Anticancer Res. 1995;15:25012510 .

* This work was presented in part at the 37th Annual Meeting of the Society of Toxicology, Seattle, WA, March 1998

$\dagger$ Corresponding author.

E-mail: michae1.graziano@pfizer.com .

Tel: +1 7346225123

¥ Current address: Cancer Research, Pfizer Global Research and Development, 2800 Plymouth Road, Ann Arbor, MI 48105, USA

$\$$ Current address: Department of Surgery, Section of Urology, University of Michigan Medical Center, Ann Arbor, MI 48109, USA 

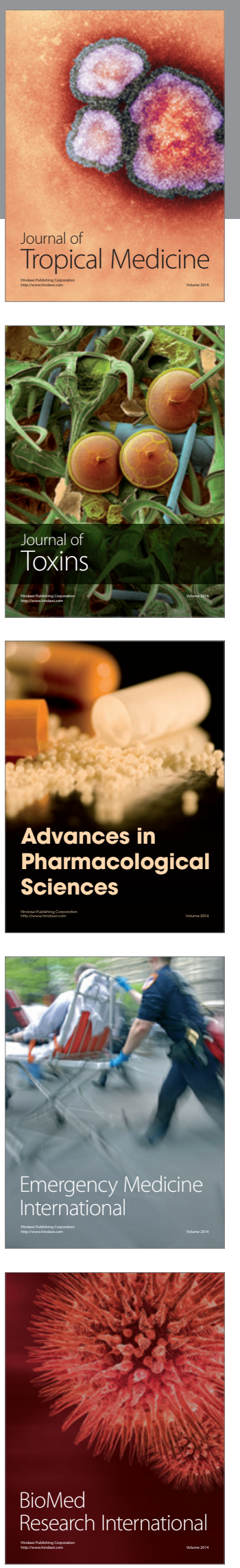
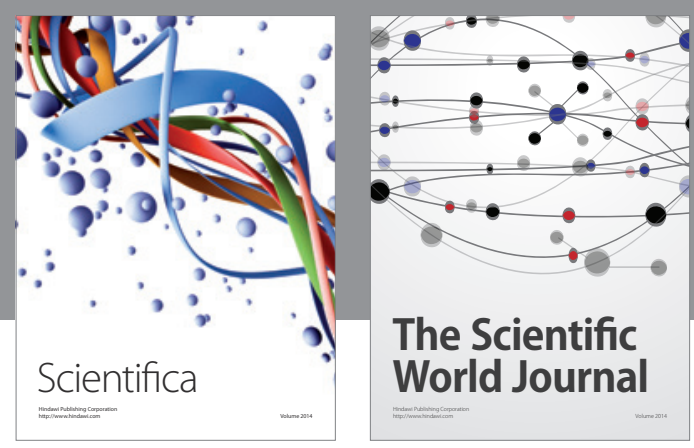

The Scientific World Journal
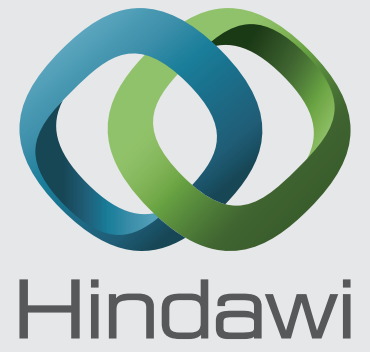

Submit your manuscripts at

http://www.hindawi.com
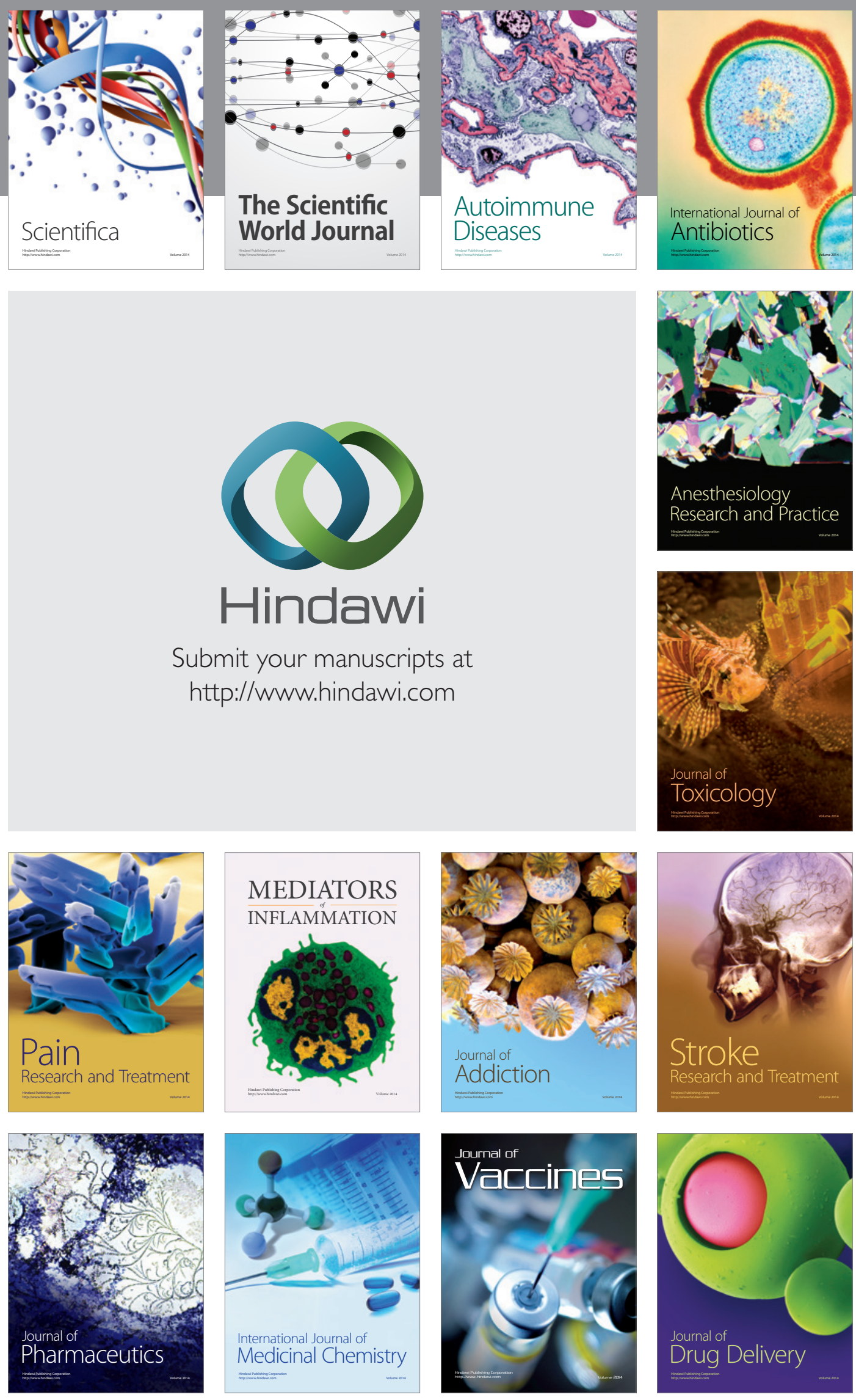